\title{
Physiological Effects of Light Intensity on the Opportunistic Algae Ulva rigida C. Agardh (Chlorophyta)
}

\author{
Gamze Yıldız*, Şeyma Tiryaki \\ Uludağ Üniversitesi Fen Edebiyat Fakültesi Biyoloji Bölümü, 0224 2941867, \\ gamze@uludag.edu.tr : seymameric@gmail.com.tr \\ *Corresponding Author \\ Received: 28 December 2016 \\ Accepted: 12 June 2017 \\ DOI: $10.18466 /$ cbayarfbe.339316
}

\begin{abstract}
Intertidal seaweeds exposed to strong fluctuation in light quantity and spectral light quality. Light plays an important role controlling seaweed growth and physiology. Therefore, we conducted a culture experiment to determine the physiological effects of light intensity on the opportunistic algae Ulva rigida C. Agardh. For this reason, samples were exposed to two different light intensities (55 $\mu \mathrm{mol}$ photons $\mathrm{m}^{-2} \mathrm{~s}^{-1}$ and $100 \mu \mathrm{mol}$ photons $\mathrm{m}^{-2} \mathrm{~s}^{-1}$ ) and their some physiological features including photosynthetic performance, growth rate, pigment content, total protein and nitrate reductase activity were measured. According to our results, the maximum relative electron transport rate and saturation irradiance point were not significantly different between the treatments. On the other hand, relative growth rate, nitrate reductase activity and chlorophyll- $a$ concentrations of $U$. rigida were significantly decreased under low light condition. Consequently, our data indicated that photosynthetic perfomance of Ulva rigida was not affected to treated light intensity, while growth and nitrogen metabolism were primarily controlled by light.
\end{abstract}

Keywords - Growth Rate, Light Intensity, Nitrate Reductase, Photosynthesis, Ulva rigida

\section{Introduction}

Macroalgal blooms occur worldwide and have potential to cause severe ecological and economic damage. Macroalgal blooms in coastal areas are largely composed of fast growing species that rapidly utilize resources, including many species in the genus Ulva L.[1]. Ulva species are considered opportunistic because of their simple thallus, fast growth rate, high surface area to volume ratio and capacity to rapidly metabolize inorganic nitrogen [2].

Ulva blooms are a common occurrence at Bursa coast and these blooms have increased in frequency and duration over the last years. Blooms frequently occurred in the late spring and summer, rarely observed in the late fall and winter at the temperate regions [3]. This blooms caused to decrease dissolved oxygen at the water column, which can result in fish kills, suffocation of benthic fauna and reduced shellfish recruitment [4]. Moreover, blooms interfere with coastal commercial and recreational activities [5].

Intertidal seaweeds exposed to strong fluctuation in light quantity and spectral light quality [6]. Light plays an important role on controlling seaweed growth and physiology.
Many researchers reported that Ulva species have been saturated photosynthesis at the current inorganic carbon pool of seawater under saturated light intensity [7]. However, growth rate of Ulva varies with environmental parameters such as light. Therefore, the aim of this study was to assess how light intensity affects the physiology and abundance of common bloom forming alga Ulva rigida C. Agardh.

\section{Materials and methods \\ 2.1 Algal material and Experimental set-up}

$U$ rigida cultures at the Uludag University (Turkey) were used for this study. The algae were originally collected from the south shore of the Sea of Marmara in the Bursa-Zeytinbagi region of Turkey ( $\left.40^{\circ} 22.8^{\prime} \mathrm{N}, 28^{\circ} 48.0^{\prime} \mathrm{E}\right)$. The algal blades were preincubated for 2 days at $20^{\circ} \mathrm{C}$, a salinity of 23 which is the natural salinity level for Sea of Marmara, $55 \mu \mathrm{mol}$ photons $\mathrm{m}^{-2} \mathrm{~s}^{-1}$ light intensity and a $12: 12 \mathrm{~h}$ light:dark cycle in filtered artificial seawater containing $1 / 4$ strength Provasoli enrichment medium [8]. Calcium chloride $\left(\mathrm{CaCl}_{2} 2 \mathrm{H}_{2} \mathrm{O}\right)$ was added to the enrichment medium to a final concentration of $10 \mathrm{mM}$ to ensure the presence of calcium. Thalli used in the experiment were carefully selected from cultures and cleaned of epiphytes. For cultivation, thalli were cut into discs of $2 \mathrm{~cm}$ in diameter. Discs of 
the $U$. rigida were acclimated for 3 days in a light and temperate controlled growth chamber before the experiment. Culture conditions were prepared with two different irradiation conditions ( $55 \mu \mathrm{mol}$ photons $\mathrm{m}^{-2} \mathrm{~s}^{-1}$ and $100 \mu \mathrm{mol}$ photons $\mathrm{m}^{-2} \mathrm{~s}^{-1}$ ). Each treatment was repeated four times in four independent experiments where each treatment was replicated once. Samples were incubated in glass tanks containing $15 \mathrm{l}$ of filtered artificial seawater. Each tank initially contained 20 discs of $U$. rigida. The seawater was filtered through a Whatman polycap capsule filter $(0.45 \mu \mathrm{m}$ pore size) and circulated in each tank using magnetic stir bars. To avoid nutrient depletion culture medium was renewed every 3 days. During the light period, desired PAR (400$700 \mathrm{~nm}$ ) levels were provided by one or three Osram daylight fluorescence tube (Osram Luminux Plus Daylight L18W/11-860, Munich, Germany). Light measurements were made with a LI-COR 250A underwater quantum sensor 192A.

\subsection{Photochemical measurements}

Optimum quantum yield of photosystem II was determined by measuring variable chlorophyll fluorescence of PSII with a PAM 2500 device (Walz, Germany) following the methods by Bischof et al. [9]. maximum quantum yield $(\mathrm{Fv} / \mathrm{Fm})$ was calculated as the ratio of variable to maximum fluorescence of dark acclimated algae for $10 \mathrm{~min}$. Additionally, samples were irradiated with increasing levels of actinic light. Every $30 \mathrm{~s}$, a saturating pulse was applied to measure effective quantum yield of photosynthesis before actinic irradiation was increased again. The parameters initial linear slope (alpha), maximum relative electron transport rate (rETRmax) and saturation irradiance (Ik) were calculated from the photosynthesis and light data using the Eilers and Peeters [10] model. All photochemical measurements were performed in the same medium used for the treatment.

\subsection{Growth and Biochemical Measurements}

Relative growth rates (RGR) were determined by measuring the fresh weight of one marked algal thallus in each treatment tank over time after blotting the thalli dry with paper towels. RGR expressed as percent of fresh weight per day $\left(\% \mathrm{FW} \mathrm{d}^{-1}\right)$ were calculated as $\ln \left(\mathrm{W}_{\mathrm{t}} / \mathrm{W}_{\mathrm{o}}\right) / \mathrm{t} \times 100$, where $W_{t}$ and $W_{o}$ are the fresh weights at time $t$ (days) and the initial fresh weight, respectively.

For the determination of chlorophyll- $a$ and $b$ contents, samples were extracted with N,N-dimethylformamide for $12 \mathrm{~h}$ at $4^{\circ} \mathrm{C}$ in the dark, after which, the absorbance of extracts was measured spectrophotometrically and concentrations were calculated according to Inskeep and Bloom [11]. Total protein content was determined spectrophotometrically at
$595 \mathrm{~nm}$ and concentrations were calculated by comparing with a calibration curve of bovine serum albumin [12].

Nitrate reductase activity of $U$. rigida was measured using fresh material directly from the cultures according to the in situ method improved for $U$. rigida by Corzo and Niell [13]. Fresh algal discs were placed into $5 \mathrm{ml}$ incubation medium (0.1 M phosphate buffer, 0.5 mM EDTA, 0.1\% 1-propanol, $30 \mathrm{mM} \mathrm{KNO}_{3}$ and $10 \mu \mathrm{M}$ glucose; $\mathrm{pH} 8.0$ ), which is bubbled with $\mathrm{N}_{2}$ gas before and after introducing the algal discs for $2 \mathrm{~min}$. After the incubation in the dark at $20^{\circ} \mathrm{C}$ for 30 min, $1 \mathrm{ml}$ of the assay buffer was removed and the nitrite concentrations were determined colorimetrically [14] after the addition of $200 \mu \mathrm{l}$ of $4 \%$ sulphanilimide and $300 \mu \mathrm{l}$ of $0.1 \% \mathrm{n}$-(1-naphthyl ethylenediamine dihydrochloride.

\subsection{Statistics}

Data are presented as the mean \pm standard error. Data were tested for normality (Kolmogorov-Smirnov test) and subjected to Levene's test to verify the homogeneity of variances among groups. Two-way anova or t-test was used to establish differences among treatments at a level of $p<0.05$. The analyses were carried out with the commercial software program SPSS 17.0 (IBM Corporation).

\section{Results}

Table 1 presents the mean of maximum quantum yield (Fv/Fm), initial linear slope (alpha), saturation irradiance point (Ik) and rETRmax of $U$. rigida exposed to the different light conditions. In this study, the mean $\mathrm{Fv} / \mathrm{Fm}$ ratios of Ulva rigida exposed to low and high light conditions were significantly different between the treatments $\left(F_{5,30}=\right.$ 27.943, $p=0.000$, Table 1). Unlike the light intensity, the incubation time was not impact the $\mathrm{Fv} / \mathrm{Fm}$ ratio $\left(F_{5,30}=\right.$ $3.020, p=0.064)$. Similarly, there was not interaction between the light intensity and incubation time $\left(F_{5,30}=2.890\right.$, $p=0.071$ ). The alpha represents the ETR efficiency of PSII at low irradiance. Alpha values in this study significantly decreased with low light. The rETRmax as a function of increasing actinic light intensity and saturation irradiance point were not significantly different between the treatments $\left(F_{5,30}=0.525, p=0.474 ; F_{5,30}=2.677, p=0.112\right.$, respectively).

Total protein content of $U$. rigida was not significantly affected by light intensity $(p=0.780)$ after 21 days (Table 2$)$. On the other hand, RGR based on fresh weight and nitrate reductase activity were significantly decreased under low light condition ( $p=0.037 ; p=0.014$, respectively). The average RGR was $4.79 \%$ day $^{-1}$ in the high light treatment, but decreased to $2.83 \%$ day $^{-1}$ in low light treatment (Figure 1). Similarly, the mean nitrate reductase activity was $5.01 \mathrm{U}$ $\min ^{-1}$ in the high light treatment, but decreased to $1.82 \mathrm{U}$ $\mathrm{min}^{-1}$ in the low light treatment (Figure 2). 
Table 1. Means $( \pm \mathrm{SD})$ of the maximum quantum yields $(\mathrm{Fv} / \mathrm{Fm})$, maximum relative electron transport rate (rETRmax), initial linear slope (alpha) and light saturation points (Ik) of $U$ rigida exposed to different light intensity.

\begin{tabular}{|c|c|c|c|c|c|}
\hline & & Fv/Fm & rETRmax & alpha & Ik \\
\hline \multirow{2}{*}{ Week-1 } & High light & $0.744 \pm 0.004$ & $39.18 \pm 1.16$ & $0.363 \pm 0.006$ & $108.07 \pm 4.11$ \\
\cline { 2 - 6 } & Low light & $0.767 \pm 0.003$ & $39.03 \pm 1.13$ & $0.345 \pm 0.006$ & $113.23 \pm 3.20$ \\
\hline \multirow{2}{*}{ Week-2 } & High light & $0.753 \pm 0.004$ & $36.23 \pm 1.72$ & $0.345 \pm 0.007$ & $105.10 \pm 4.74$ \\
\cline { 2 - 6 } & Low light & $0.772 \pm 0.005$ & $38.12 \pm 2.61$ & $0.339 \pm 0.009$ & $113.03 \pm 8.68$ \\
\hline \multirow{2}{*}{ Week-3 } & High light & $0.761 \pm 0.002$ & $35.60 \pm 1.45$ & $0.353 \pm 0.005$ & $100.94 \pm 4.22$ \\
\cline { 2 - 6 } & Low light & $0.767 \pm 0.003$ & $37.00 \pm 2.05$ & $0.337 \pm 0.006$ & $109.63 \pm 5.89$ \\
\hline
\end{tabular}

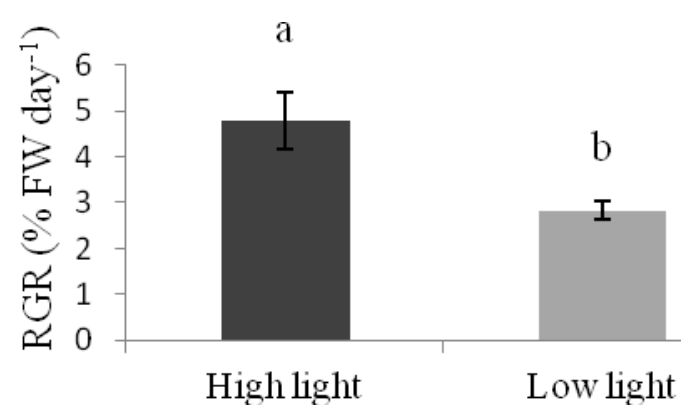

Figure 1. Means $( \pm \mathrm{SD})$ of the relative growth rate of $U$ rigida exposed to different light intensity after 21 days.

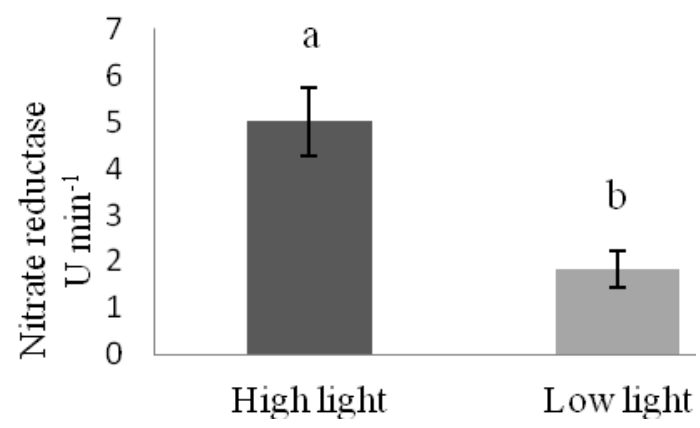

Figure 2. Means $( \pm \mathrm{SD})$ of the nitrate reductase activity of $U$ rigida exposed to different light intensity after 21 days.

The mean photosynthetic pigment concentrations of $U$. rigida exposed to different light intensity are displayed in Table 2. Content of pigments give fundamental information on the light harvesting. Chlorophyll- $b$ concentrations were not significantly affected by light intensity ( $p=0.418)$. However, chlorophyll- $a$ contents of samples ranged from 2.16 to $2.88 \mathrm{mg} \mathrm{g}^{-1}$ and chlorophyll- $a$ concentrations of $U$. rigida were significantly decreased by exposure to low light $(p=0.023)$.

Table 2. Means ( \pm SD) of the total protein, chlorophyll-a and chlorophyll-b of $U$ rigida exposed to different light intensity.

\begin{tabular}{|c|c|c|c|}
\hline & $\begin{array}{c}\text { Total protein } \\
\left(\mathrm{mg} \mathrm{g}^{-1}\right)\end{array}$ & $\begin{array}{c}\text { Chlorophyll- } \\
a \\
\left(\mathrm{mg} \mathrm{g}^{-1}\right)\end{array}$ & $\begin{array}{c}\text { Chlorophyll- } \\
b \\
\left(\mathrm{mg} \mathrm{g}^{-1}\right)\end{array}$ \\
\hline $\begin{array}{c}\text { High } \\
\text { light }\end{array}$ & $6.94 \pm 0.45$ & $2.73 \pm 0.05$ & $2.25 \pm 0.04$ \\
\hline $\begin{array}{l}\text { Low } \\
\text { light }\end{array}$ & $7.11 \pm 0.38$ & $2.40 \pm 0.10$ & $2.20 \pm 0.05$ \\
\hline
\end{tabular}

\section{Discussion and Conclusion}

Pulse Amplitude Modulation technique has been widely used for ecophysiological studies [15]. Among the fluorescence parameters Fv/Fm ratio, which is the ratio of the variable to the maximum fluorescence after dark adaptation, indicates the efficiency of energy transferred from the antenna systems to the reaction centers of PSII and it has been used as an stress indicator.

In this study, decreasing Fv/Fm ratio indicated that samples were photosynthetically stressed under high light condition. Krause and Weis [16] indicated that decreased Fv/Fm reflects absorbed energy dissipated as heat. These data indicate that decrease of Fv/Fm at the high light here may related to change in the antenna composition. Higher alpha and chlorophyll-a contents at the high light condition supported to this idea. The alpha represents the ETR efficiency of PSII at low irradiance levels. Alpha values in this study significantly increased at high light treatment. But, increased antenna size at the high light treatment due to higher pigment contents was not effected rETRmax. We expected that photosynthetic efficiency would increase with increasing light, because more light is available for photosynthesis. The 
unexpected rETRmax values at the different light intensities showed that photosynthesis of $U$. rigida was saturated at the both treatments. Growth rate is the most important parameters to determine the ecological success for seaweeds. In this study, growth rate was stimulated with higher light intensity. Rautenberger et. al. [17] also reported growth is limited by light. Similarly, nitrate reductase activity of samples exposed to high light intensity was drastically increased to support higher growth. Nitrate reductase catalyzes the reduction of nitrate to nitrite, which is usually identified as the rate-limiting step in nitrate assimilation by algae [18]. Many studies also reported that nitrate reductase activity can vary with light regimes [19, 20, 21]. Moreover, the growth rate of $U$. rigida was entirely governed by $\mathrm{N}$ assimilation.

In conclusion, physiological features of $U$. rigida was sensitive to light intensity. Photosynthetic perfomance was not affected to treated light intensity, while growth and nitrogen metabolism were primarily controlled by light. $U$. rigida act as a opportunistic and invasive species in coastal areas of Turkey. According to our results, blooms of $U$. rigida could be expecially occur at intertidal zone due to stimulated growth, because more light is available at intertidal zone than subtidal.

\section{Acknowledgements}

Funding for this project was provided by the Scientific Research Projects unit of Uludag University through the Project of HDP (F)-2012/30

\section{References}

1. Smetacek, V.; Zingone, A. Green and golden seaweed tides on the rise. Nature, 2013; 504, 84-88.

2. Cohen, I,; Neori, A. Ulva lactuca Biofilters for Marine Fishpond Effluents. Botanica Marina, 1991; 34, 475-482.

3. Rinehard, S.; Guidone, M.; Ziegler, A.; Schollmeier T.; Thornber, C.S. Overwintering strategies of bloom-forming Ulva species in Narragansett Bay, Rhode Island, USA. Botanica Marina, 2014; 57(4), 337-341.

4. Thomsen, M.; McGlathery K. Effects of accumulations of sediments and drift algae on recruitment of sessile organisms associated with oyster reefs. Journal of Experimental Marine Biology and Ecology, 2006; 328, 22-34.

5. Deacutis, C. Evidence of Ecological Impacts from Excess Nutrients in upper Naragansett Bay. Science for Ecosystem Based Management; Desbonnet, A., Costa-Pierce, B.A., Eds.; Springer: New York, 2008; 349381.

6. Hader, D.P.; Figueroa, F.L. Photoecophysiology of Marine Macroalgae. Journal of Photochemistry and Photobiology B: Biology, 1997; 66, 114.
7. Mercado J.M.; Gordillo, F.J.L.; Figueroa, F.L.; Niell, F.X. External carbonic anhydrase and affinity for inorganic carbon in intertidal macroalgae. Journal of Experimental Marine Biology and Ecology, 1998; 221, 209-220.

8. Provasoli, L. Media and Prospects for the Cultivation of Marine Algae: Cultures and Collections of Algae. Proceedings of the US-Japan Conference, Hakone, September 1966; JPN. Soc. Plant Physiol. 1968; 63-75.

9. Bischof, K.; Hanelt, D.; Wiencke, C. Acclimation of Maximal Quantum Yield of Photosynthesis in the Brown Alga Alaria esculenta under High Light and UV Radiation. Plant Biology, 1999; 1, 435-444.

10. Eilers, P.H.C.; Peeters, J.C.H. A Model for the Relationship Between Light Intensity and the Rate of Photosynthesis in Phytoplankton. Ecological Modelling, 1988; 42, 199-215.

11. Inskeep, W.P.; Bloom, P.R. Extinction Coefficients of Chlorophyll a and b in N,N-dimethylformamide and $80 \%$ Acetone, Plant Physiology, 1985; 77, 483-485.

12. Bradford, M. A Rapid and Sensitive Method for the Quantization of Microgram Quantities of Protein Utilizing the Principle of Protein-Dye Binding. Analytical Biochemistry, 1976; 72, 248-254.

13. Corzo, A.; Niell, F.X. Determination of Nitrate Reductase Activity in Ulva rigida C. Agardh by the in situ Method, Journal of Experimental Marine Biology and Ecology, 1991; 146, 181-191.

14. [Snell, F.D.; Snell, C.T. Colorimetric Methods of Analysis, Vol. 2, $3^{\text {rd }}$ edn. Princeton, NJ:Van Nostrand, 1949.

15. Maxwell, K.; Johnson, G.N. Chlorophyll Fluorescence- a practical Guide. Journal of Experimental Botany, 2000; 51, 659-668.

16. Krause, G.H.; Weis, E. Chlorophyll Fluorescence and Photosynthesis: the Basics. Annual Review of Plant Physiology and Plant Molecular Biology, 1991; 42, 313-349.

17. Rautenberger, R.; Fernandez, P.A.; Strittmatter, M.; Heesch, S.; Cornwall, C.E.; Hurd, C.L.; Roleda, M.Y. Saturating Light and not Increased Carbon Dioxide under Ocean Acidification Drives Photosynthesis and Growth in Ulva rigida (Chlorophyta). Ecology and Evolution, 2015; 5(4), 874- 888.

18. Young, E.B.; Berges, J.A.; Dring, M.J. Physiological Responses of Intertidal Marine Brown Algae to Nitrogen Deprivation and Resupply of Nitrate and Ammonium. Physiologia Plantarum, 2009; 135, 400-411.

19. Chow, F.; Oliveira, M.C.; Pedersen M. In vitro assay and light regulation of nitrate reductase in red alga Gracilaria chilensis. Journal of Plant Physiology. 2004; 161, 769-776.

20. Young, E.B.; Dring, M.J.; Berges, J.A. Distinct pattern of nitrate reductase activity in Brown algae: Light and ammonium sensitivity in Laminaria digitata is absent in Fucus species. Journal of Phycology, 2007; 43, 1200-1208.

21. Pritchard, D.W.; Hurd, C.L.; Beardall, J.; Hepburn, C.D. Restricted use of nitrate and astrong preference for ammonium reflects the nitrogen ecophysiology of a light limited re dalga. Journal of Phycology, 2015; 51, 277-287. 